\title{
Posterior Mediastinal Mature Teratoma: A Case Report and Literature Review
}

\author{
Sani Rabiou ${ }^{1}$, Jamal Ghalimi1 ${ }^{1}$ Marwane Lakranbi1, Yassine Ouadnouni ${ }^{1,2}$, \\ Mohamed Smahi ${ }^{1,2}$ \\ ${ }^{1}$ Department of Thoracic Surgery, University Hospital Hassan II, Fez, Morocco \\ ${ }^{2}$ Faculty of Medicine and Pharmacy, Sidi Mohamed Benabdellah University, Fez, Morocco \\ Email: rabiousani2@yahoo.fr
}

Received 22 December 2013; revised 20 January 2014; accepted 15 February 2014

Copyright (C 2014 by authors and Scientific Research Publishing Inc.

This work is licensed under the Creative Commons Attribution International License (CC BY). http://creativecommons.org/licenses/by/4.0/

(c) (i) Open Access

\begin{abstract}
Mediastinal mature teratoma is the most common form of germ cell tumors, often located in the anterior mediastinum. A posterior mediastinum location has rarely been described. We report a case of a posterior mediastinal mature teratoma in a 37-year-old patient and a literature review, through which we describe the diagnostic and therapeutic difficulties inherent in this particular location of these tumors.
\end{abstract}

Keywords

Posterior Mediastinal Mature Teratoma; Computed Tomography; Surgery

\section{Introduction}

Teratomas are encapsulated tumors derived from the three primary germ layers; Mesoderm, Endoderm and Ectoderm. These are rare tumors in young patients and their location in the posterior mediastinum has not been the subject of many publications [1]. We report a case of a posterior mediastinal mature teratoma (MMT) in a patient of 37 years.

\section{Case Presentation}

Mr. I. S. smoked for 14 years, weaned, presents with a right chest pain, progressively worsening over month. Except a right chest effusion syndrome, clinical examination was unremarkable. The routine laboratory tests were normal. A chest X-ray radiograph (Figure 1(a)) showed a well-circumscribed rounded homogeneous post

\footnotetext{
${ }^{*}$ Corresponding author.
}

How to cite this paper: Rabiou, S., Ghalimi, J., Lakranbi, M., Ouadnouni, Y. and Smahi, M. (2014) Posterior Mediastinal Mature Teratoma: A Case Report and Literature Review. Case Reports in Clinical Medicine, 3, 122-124. 


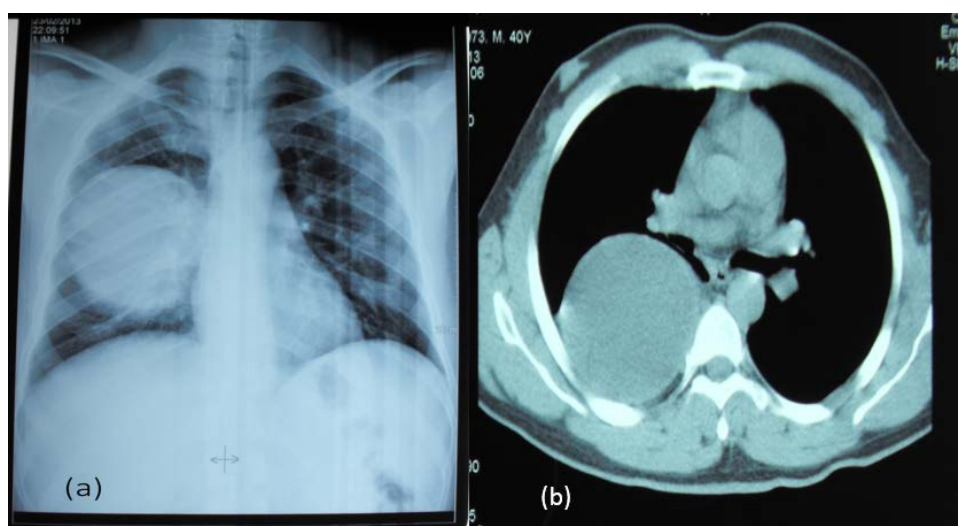

Figure 1. (a) Chest X-ray showed a well-defined rounded opacity of the right hemi thorax. (b) CT with injection of contrast showed a heterogeneous cystic lesion with fat, fluid levels on the right costovertebral groove.

erior opacity of the right hemithorax. The computed tomography (CT) scan with injection of contrast showed a heterogeneous cystic lesion with fat, fluid levels on the right costovertebral groove with regular lung interface. There were no signs of invasion (Figure 1(b)). The diagnosis of posterior mediastinal teratoma was retained not excluding a neurogenic tumor or a liposarcoma. A right postero lateral thoracotomy was decided. Intraoperatively we found a cystic mass containing brownish liquid in the posterior mediastinum. The mass was in intimate contact with the esophagus, the right main bronchus, the right atrium and the right lower pulmonary vein. Complete excision of the mass was performed with extreme caution. The final histopathological examination confirmed the diagnosis of a mature cystic teratoma without mediastinal immature or malignant tissues (Figure 2). The immediate post-operative evolution was simple, chest catheter was off at day 3 and patient was discharged at day 5 after surgery. The clinical and radiological control was satisfactory at three months later.

\section{Discussion}

A mediastinum location of a teratoma is uncommon $4 \%-10 \%$ [1]. It represents however $60 \%$ of embryonic mediastinal tumors and it is mature in $80 \%$ to $88 \%$ of cases [2]. The posterior mediastinum is the usual site of neurogenic tumors (80\% - 90\%), para oesophageal cysts, and mesenchymal tumors including liposarcomas. Only $3 \%-8 \%$ of mediastinal teratoma [3] is located in the posterior mediastinum. In adults, the discovery of a mediastinal teratoma is often accidental, when performing a routine chest radiograph. It is a large mass, well-circumscribed and lobulated, with calcifications in $20 \%$ of cases [4]. A CT scan is the choice investigation, it specifies the location of the mass, and highlights a combination of fluid density, fat and calcifications in $40 \%$ of cases, highly suggestive of mediastinal teratoma [4]. It also examines the relations of the mass with adjacent organs, indicating the presence or absence of tumor border and regularity of tumor interface with the lung and adjacent mediastina structures, and the possibility of surgery. The discovery on chest CT of a heterogeneous process with cystic fluid density and fat allowed us to suggest the diagnosis of teratoma in our patient. Treatment is surgical. It confirms the diagnosis by eliminating the presence of an immature component and prevents the occurrence of complications [5]. Posterior lateral thoracotomy remains the most ideal way for surgery. Video-assisted surgery is often limited by the large size of teratomas and the frequency of adhesions with noble mediastina structures, as we report in this case [6]. From a histological point of view, mature benign teratoma occur readily as cystic tumors composed in varying proportions of different tissues having attained a high degree of differentiation. They can however be composed of skin, cartilage, calcifications, smooth muscle, bronchial epithelium or rarely thymus tissue, pancreas, or thyroid [7]. This pluritissulaire constitution with a respiratory epithelium and the presence of smooth muscle is also found in our study.

\section{Conclusion}

The posterior mediastinum is a rare seat of MMT. CT is the modality of choice in the diagnosis of these tumors, regardless of their location. Surgery remains the ideal treatment to confirm the diagnosis, prevent complications and eliminating the existence of immature component, whose presence would indicate the adjuvant therapy. 


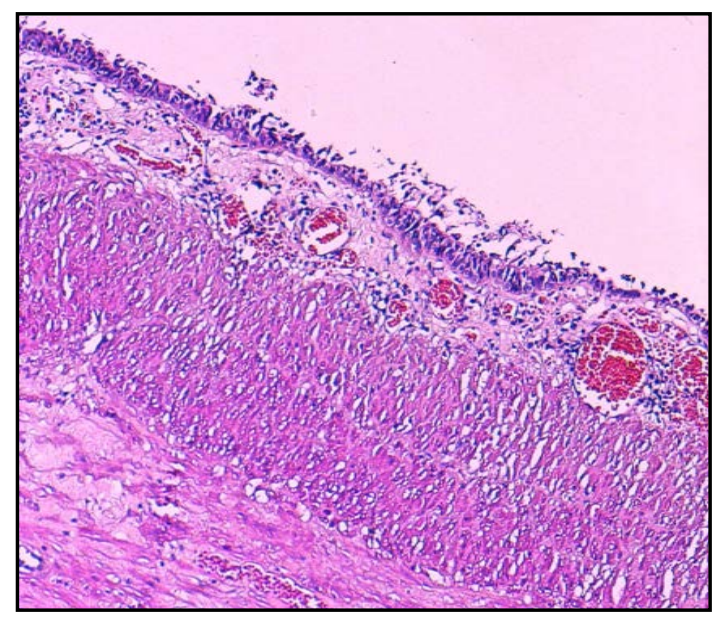

Figure 2. (HES 100×) Histology of the teratoma, with mature differentiated tissue of various origin.

\section{Consent}

Written informed consent was obtained from the patient for the study and publication of this case report and accompanying images. A copy of written consent is available for review from the Editor-in-Chief.

\section{Authors' Contributions}

SR collected information and prepared the original draft. ML and JG researched the relevant literature and revised the draft. YO helped with the literature research and preparing the manuscript. MS helped prepare the manuscript. All authors read and approved the final manuscript.

\section{Competing Interests}

The authors declare that they have no competing interests.

\section{References}

[1] Smahi, M., Achir, A., Chafik, A., et al. (2000) Mediastinal Mature Teratoma: About 12 Cases. Annales de Chirurgie, 125, 965-971. http://dx.doi.org/10.1016/S0003-3944(00)00410-7

[2] De Bournonville, C., Maugendre, S., Belleguic, C., et al. (1999) Mediastinal Mature Teratoma: About 2 Cases. Revue de Pneumologie Clinique, 55, 177-180.

[3] Kurosaki, Y., Tanaka, Y.O. and Itai, Y. (1998) Mature Teratoma of the Posterieur Mediastinium: Case Report. European Radiology, 8, 100-102. http://dx.doi.org/10.1007/s003300050347

[4] Moeller, K.H., Rosado-De-Christenson, M. and Templeton, P.A. (1997) Mediastinal Mature Teratoma: Imaging Features. American Journal of Roentgenology, 169, 985-990. http://dx.doi.org/10.2214/ajr.169.4.9308448

[5] Zidane, A., Arsalane, A., Atoini, F., et al. (2008) Mature Mediastinal Teratoma Mimicking a Thoracic Extrapulmonary Hydatid Cyst. Revue de Pneumologie Clinique, 64, 141-142. http://dx.doi.org/10.1016/j.pneumo.2008.04.012

[6] Beduneau, G., Cuvelier, A., Héliot, P.H., et al. (2002) Mediastinal Teratoma with Recurrent Encysted Pleural Effusion Revue des Maladies Respiratoires, 19, 367-370.

[7] Mosk, C.A., Van de Ven, C.P., Bessems, J.H.J.M., et al. (2013) Unusual Presentation of a Posterior Mediastinal Teratoma. Journal of Pediatric Surgery Case Reports, 1, 164-166. http://dx.doi.org/10.1016/j.epsc.2013.05.013

\section{Abbreviations}

MMT: Mature mediastinal teratoma

CT: Computed tomography 